\title{
Degenerative diseases of the central nervous system transmissible to experimental animals
}

\author{
ELISABETH BECK \\ P. M. DANIEL \\ Department of Neuropathology, Institute of Psychiatry, The Maudsley Hospital, \\ De Crespigny Park, Denmark Hill, London, S.E.5
}

\section{Summary}

The clinical features and the pathological changes in the central nervous system of scrapie and kuru are described and attention is drawn to the similarities between these conditions. In both, inoculation of tissues into experimental animals reproduces a similar disease after a prolonged latent period.

The transmission of subacute presenile polioencephalopathy to a chimpanzee is noted.

The work which led to the discovery of the transmissibility of these conditions is mentioned.

\section{Introduction}

The aetiology of many of the chronic or subacute degenerative conditions of the human central nervous system has remained unknown from the time that they were first recognized as pathological entities, within the last 50 years, up to the present. As sometimes happens the first clue indicating that a chronic neurological disease of degenerative type might have an identifiable cause came from the world of animal disease. The disease in question was scrapie in sheep.

In 1935 experiments for the mass-production of a vaccine to combat louping-ill, an interesting virus infection of the nervous system of sheep, had been concluded and vaccination of sheep had been started on a large scale (Gordon, 1946). The vaccine was gained by infecting healthy sheep and collecting their brains, spinal cords and spleens 5 days after inoculation. From these tissues a suspension was made, with the addition of formalin to inactivate the virus. Sheep were vaccinated and although they were protected from infection with louping-ill, a number developed scrapie 2 years after vaccination. Since these flocks had previously been free from scrapie, Gordon (1946) suspected a connection between the vaccination and the subsequent outbreak of scrapie in these flocks. By tracing back the source of the vaccine he discovered in fact that siblings of a number of animals from whose brains the vaccine had been prepared had now gone down with scrapie. He had thus unexpectedly supported the findings from the small series of experiments on the trans- missibility of scrapie by Cuillé \& Chelle (1939) on a large scale and thus firmly established the transrnissibility of one of the obscure degenerations of the central nervous system. Subsequently Gordon embarked upon an extensive series of experiments designed to investigate the transmission of scrapic and during the course of many years was able to show that brain tissue from sheep with scrapie could be subjected to many severe insults, such as boiling or immersion in formalin and yet would still induce the development of scrapie in the recipient sheep. This long-continued investigation remained something of an experimental curiosity for a considerable time and was thought of as an interesting example of the way in which experimental mistakes lead to new and unexpected findings (Beveridge, 1961). Gordon's work was followed by that of Sigurdsson (1954) who established a similar transmissibility of various other animal diseases including rida, the Icelandic form of scrapie, and coined the term 'slow virus infection'. His criteria were: 'A very long initial period of latency lasting from several months to several years. A rather regular protracted course after clinical signs have appeared usually ending in serious disease or death. Limitation of the infection to a single host species and anatomical lesions in only a single organ or tissue system.'

The next step forward came as a result of the recognition of kuru as an entirely new and previously unknown disease by Gajdusek \& Zigas in 1957. This new disease occurred only amongst the Fore people, living in a completely isolated region in the Eastern Highlands of New Guinea (Gajdusek, $1963,1965)$. These people had had virtually no contact with the outside world until after the Second World War, and then had only occasionally been visited by an administrative officer or a missionary. The disease that Gajdusek and Zigas reported was characterized by ataxia and tremor and progressed remorselessly to death within a year. In the Fore tongue 'kuru' means trembling from cold or fear, and it accounted for about half the deaths in the community. It was at first thought that the condition was some sort of an encephalitis, but the lack of 
fever and absence of pleocytosis or of raised protein in the cerebrospinal fluid rendered this idea unlikely. Pathologically the disease was found to be a subacute degeneration of the central nervous system. At first it was believed that the development of kuru was genetically determined since every case had affected relatives. But lately doubt has been thrown on the genetic basis of the disease and some workers have even suggested that the former practice of cannibalism, in which kuru patients were eaten, may have played its part in inducing the disease. The habit of cannibalism has now been given up: possibly fortuitously the incidence of the disease is diminishing.

In 1959 Hadlow commented on the similarities between kuru and scrapie. Since scrapie was known to be transmissible by intracerebral inoculation, it seemed to Gajdusek and his colleagues (Gajdusek \& Gibbs, 1964; Gajdusek, Gibbs \& Alpers, 1966) to be worthwhile to attempt the transmission of a human degenerative disease, kuru, in the same manner. Frozen specimens of cerebral tissue from patients with kuru were, therefore, brought back and suspensions of this were inoculated into the brains of a variety of animals. Of all the species of animal inoculated only the chimpanzee eventually showed signs of neurological disease, and this after a very long latent period which varied from 18 to 38 months. This long latent period was not wholly unexpected, since in sheep inoculated with scrapiebrain suspension there had also been an extremely long latent period before the recipient animals went down with the experimental disease. The onset of the experimental disease in the chimpanzees was marked by ataxia. The animals started to become clumsy in their movements and when stretching out a hand to take a proffered apple would miss the object on the first attempt. The ataxia steadily progressed so that after a while difficulty in standing was noted and eventually the picture of a severe cerebellar ataxia presented, the animals becoming totally incapacitated. In the terminal stages they appeared to have impairment of vision. Death occurred after about 6 months. The neuropathological picture was that of an extensive degeneration throughout the cerebral hemispheres, brain-stem and cerebellum. Eight chimpanzees were given intracerebral inoculations of brain suspension from seven patients who had died from kuru and all these animals developed the experimental disease.

Brain suspension from the first series of animals was inoculated intracerebrally into another series of chimpanzees and these have again gone down with the same clinical picture as the first series and the brains showed identical histological changes. One of the second series of animals was not given the inoculum intracerebrally but peripherally and this chimpanzee also developed the typical clinical and neuropathological picture of experimental kuru. It was of interest that in the case of this second series of animals the latent period before the onset of clinical signs was shorter than in that of the series inoculated directly with human material (Gajdusek, Gibbs \& Alpers, 1967).

The neuropathological picture seen in the nervous system of all these chimpanzees with experimental kuru is astonishingly similar to that seen in another chronic neurological disease of man, subacute presenile polio-encephalopathy (a variety of Creutzfeldt-Jakob disease). This term was introduced by Brownell \& Oppenheimer (1965) to denote a disease with an onset between the ages of 40 and 60 and leading to death within a matter of months. There is usually ataxia, dysarthria, disturbance of voluntary movement (often with myoclonic jerks), cortical blindness, dysphagia and dementia. Some of these clinical features are also seen in spongiform encephalopathy or Nevin-Jones disease (Jones \& Nevin, 1954; Nevin et al., 1960). At present it is difficult to know whether these conditions can really be separated or whether they are variations of the same disease. However, the similarity of the neuropathological picture between this group of human diseases and experimental kuru, made it seem worth-o while to attempt transmission to chimpanzees. As tiopsy which histologically showed the typica spongiform state was obtained from a patient of Dr W. B. Matthews. An inoculum of this material was injected into the brain of a chimpanzee. After a latent period of 13 months this animal became ill, developing ataxia and presenting a very similar clinical picture to the chimpanzees with experimental kuru although there were certain differences. It eventually died and the investigation of the brain is not yet complete, but a preliminary survey shows that the picture although similar to that seen in the animals with experimental kuru, shows other distinct features also seen in the brain of the patient from whom the biopsy was taken (Gibbs et al., 1968).

\section{Scrapie}

Scrapie, a subacute, degenerative disease of the nervous system, has been known to affect sheep in Europe for over 200 years, and there are many useful accounts of the disease in the literature of the last century. The clinical signs include wasting, rubbing, ataxia, tremor, abnormalities of behaviour and excessive thirst, signs which have been used to give the disease its colloquial name in many countries. For example, 'scrapie' or 'the rubbers' in England, 'la tremblante' or 'maladie folle' in France and 'Traberkrankheit' in Germany.

Much of our knowledge of the clinical aspects of scrapie has come from shepherds, many of whom are 
extremely acute and accurate observers. Although rubbing is a most obvious feature and sheep with much of their fleece rubbed off are commonly seen wherever scrapie is prevalent, such features as the unusual thirst are not so readily obscrved. Yet amongst shepherds this is generaliy well known. The grossly abnormal behaviour of sheep with scrapie is also common knowledge; these animals may, on occasion, attack dogs, an action quite foreign to a normal sheep. Ataxia may be a presenting feature and has long been observed as an inability of the animal to rise after a fall.

Again shepherds were convinced that scrapie was inherited and indeed Parry $(1962,1969)$ has shown that there is a genetic factor in the disease. However, it is clear that a genetic predisposition cannot be the only factor determining the development of scrapie.

The pathology of scrapie was for long obscure and the only pathological feature which was firmly established was the presence of vacuolated neurones in the brain-stem of affected animals, a finding which did not satisfactorily explain the variety of clinical signs (for a review of the literature see Palmer, 1959; Beck, Daniel \& Parry, 1964).

In a series of thirty-four cases which we examined in 1964, well marked pathological changes were demonstrated in the cerebellum and its connections and also in the hypothalamus. Although the severity of such changes might vary from case to case they were sufficiently marked to provide a pathological basis for the most prominent of the clinical signs. There were no macroscopic abnormalities in the nervous system.

In the cerebellum there was a marked, but not uniform, loss of Purkinje and granule cells (Fig. 1) and empty baskets were seen which marked the sites

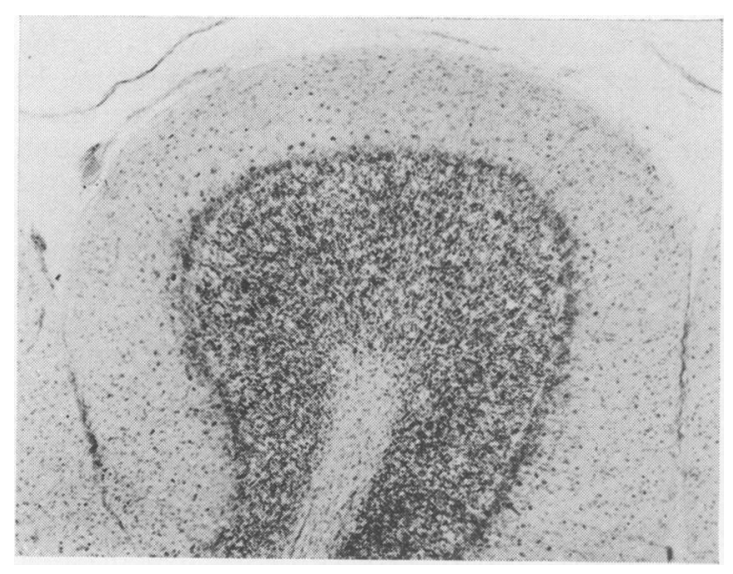

Fig. 1. Scrapie. Cerebellum; note almost complete loss of Purkinje cells and rarefaction of granule cells (below the Purkinje cell layer). Nissl stain. from which Purkinje cells had disappeared. In addition there were numbers of torpedoes on the axons of Purkinje cells (Fig. 2), which are interpreted as

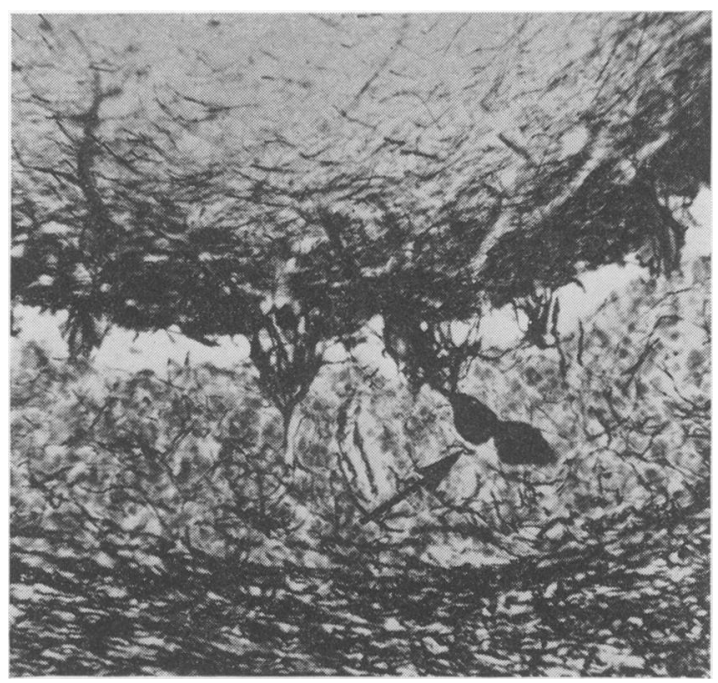

FIG. 2. Scrapie. Cerebellum; torpedo-like swelling on axon of Purkinje cell (arrow). Gros-Bielschowsky silver impregnation.

indicating that these cells are abnormal. Periodicacid-Schiff-positive plaques were found within the granular layer in four cases. Of the glial elements the astrocytes had proliferated and their processes had formed a fibrous network throughout the grey matter and the subcortical white matter (Fig. 3). (Such gliosis is often associated with degeneration in the nervous system and is never seen in the normal

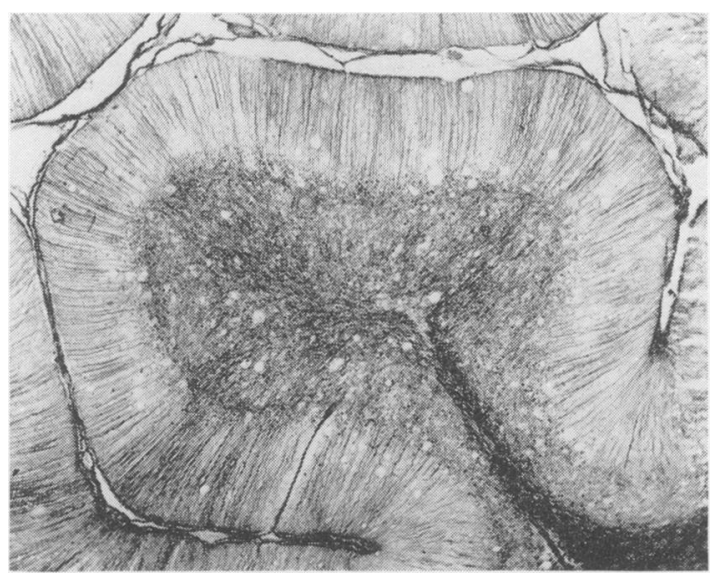

FIg. 3. Scrapie. Cerebellum; dense fibrous gliosis in both cortex and subcortical white matter. (In normal material such long and dense glial fibres are not seen.) Holzer stain. 
specimen.) The cerebellar white matter did not appear obviously demyelinated, although in the most severe cases a certain amount of neutral fat was seen indicating that some breakdown of myelin, presumably secondary to neuronal degeneration, had occurred. It was of great interest that all the nuclei of the brain-stem and spinal cord with afferent cerebellar connections showed bilateral degeneration of varying severity (pontine nuclei, inferior olives, lateral cuneate and lateral reticular nuclei and the calls of Clark's column). Such degeneration included neuronal loss and fibrous gliosis (Figs. 4 and 5). In

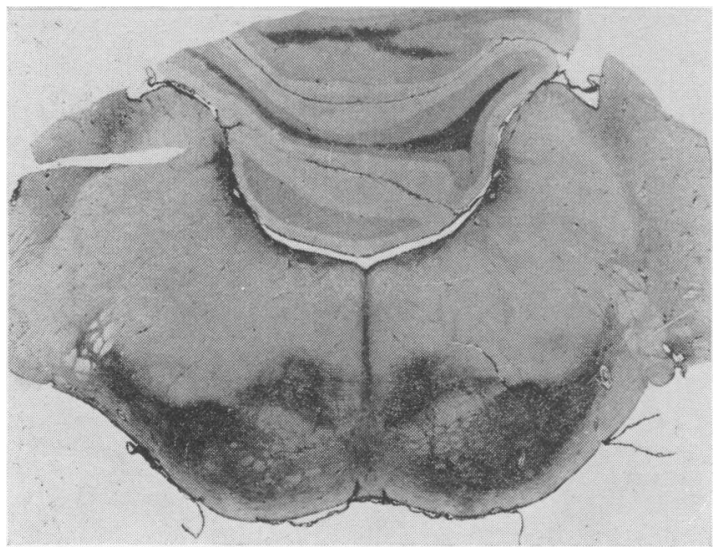

FIG. 4. Scrapie. Pons; The degenerated nuclei pontis, situated in the lower half, are stained darkly owing to the intense fibrous gliosis which is virtually confined to this territory. Note sparing of tegmentum and corticospinal tracts. Holzer stain.

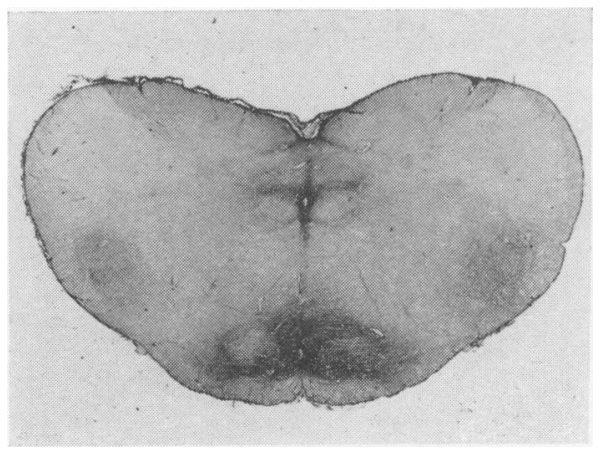

FIG. 5. Scrapie. Medulla; a similar gliosis is seen in the degenerated inferior olives which, like the pontine nuclei, are one of the main afferent pathways to the cerebellum. Holzer stain.

addition, many of the surviving neurones particularly in the lateral reticular and lateral cuneate nuclei showed coarse intracytoplasmic vacuolation (Fig. 6) which for a long time had been regarded as the main pathological feature in this disease. The changes in the

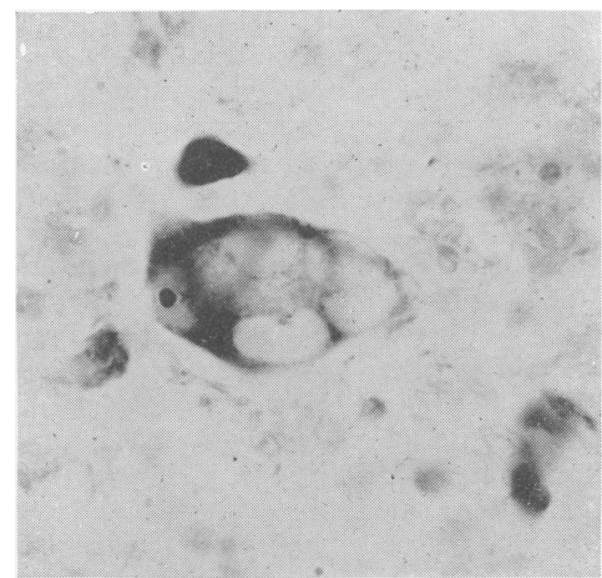

FIG. 6. Scrapie. Note multiple intracytoplasmic vacuoles and eccentric nucleus in a neurone of the lateral reticular nucleus. Such vacuolated cells are commonly found in nuclei with cerebellar connections. Nissl stain.

cerebellum and its connections give a satisfactory pathological explanation for the clinical signs of ataxia and tremor which are such a characteristic feature of the disease. We found that in general the severity of the clinical signs correlated well with the severity of the pathological changes in an individuab animal.

Apart from the cerebellar changes the mos striking degeneration was found in the hypothalamus and in particular in the supraoptic and paraventricular nuclei. These nuclei control water metabolism by producing antidiuretic hormone, and contain the cells of origin of the supraoptic-hypophysial tract which ends in the posterior lobe of the pituitary gland. Degeneration in the supraoptic (Fig. 7) and paraventricular nuclei often amounted to a considerable nerve-cell loss and fibrous gliosis. There was also an abnormality in the distribution pattern of neurosecretory material within the nuclei themselves, the tract and the posterior lobe of the pituitary gland. Thus the amount of neurosecretory material was increased in the nuclei and along the course of the tract while in the posterior lobe of the gland neurosecretory substance was conspicuously absent. This picture is reminiscent of that seen in cases of hypophysectomy or pituitary stalk section (Beck \& Daniel, 1961) where regenerating fibres from surviving nerve cells deposit neurosecretory material in places and amounts never seen in the normal. We are inclined to think that a similar regenerative process is taking place in the degenerating hypothalamo-neurohypophysial system of sheep with scrapie. The appearance of the hypothalamic nuclei is very similar to that seen in certain cases of human diabetes insipidus, and explains the excessive thirst seen in many of these animals. 


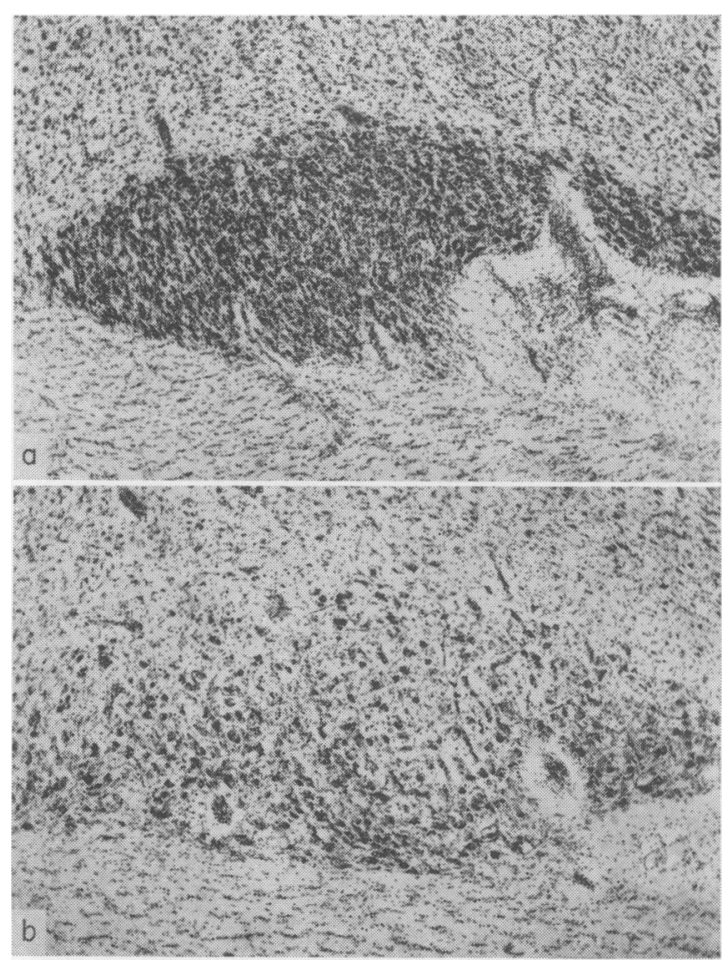

Fig. 7. (a) Normal sheep. Supraoptic nucleus of the hypothalamus. Note density of nerve cells. (b) Scrapie sheep showing great loss of nerve cells in supraoptic nucleus. Nissl stain.

In addition to such systematized degeneration there are widespread generalized changes such as astrocytic proliferation and hypertrophy throughout the brain-stem and parts of basal ganglia, and an increased number of glial cells in the cerebral white matter although the cerebral cortex remains largely intact. Perivascular cuffing with small round cells, i.e. an inflammatory reaction, was virtually absent. Generalized nerve-cell changes such as shrinkage and hyperchromasia have been described but since such changes can be produced experimentally at will (Koenig \& Koenig, 1952; Cammermeyer, 1960) their significance is quite uncertain. So far, no pathological process has been described which would explain the rubbing which gives the disease its English name. It is conceivable that some of the generalised changes in the thalamus might give rise to sensations of itch, but this is entirely speculative. The cause of the rubbing is one of the many problems still to be answered with regard to this strange disease.

\section{Experimental scrapie}

A disease resembling scrapie has been transmitted by means of intracerebral inoculation of brain suspension, obtained from sheep with scrapie, first to sheep but later also to goats, mice and a number of other laboratory animals. The disease can also be transmitted by inoculation with a suspension made from organs other than the brain; in addition these suspensions may be injected peripherally and still be effective.

The incubation time is extraordinarily long and may vary from 8 months to 5 years although in passage from animal to animal it steadily decreases.

The pathological features seen in the brains of these animals are somewhat different from those of the natural disease since in addition to the changes described above there is status spongiosus of the cerebral grey matter and a much more generalized proliferation of astrocytes throughout the brain. No inflammatory reaction is present (for details see Hadlow, 1961 ; Pattison \& Smith, 1963).

\section{Kuru}

Kuru was originally observed by missionaries when the area of the Fore people was first opened up in the early 1950s. The first clinical description was published by Gajdusek \& Zigas (1957) who described the disease as relentlessly progressive, leading to death usually within a year. It presents with ataxia and the patient develops a clumsy gait and tremor with disturbed balance. There is no paralysis (although there may be pyramidal signs in the very terminal stages). There is no sensory impairment; slurring of speech is an early feature and in the later stages patients are quite unable to talk. There is a tendency to jerky eye movements but no true nystagmus. Later dysphagia develops and this contributes to the severe wasting seen in the last stages of the disease. Death usually occurs partly from starvation and partly from decubitus ulceration. When the disease was first described the majority of cases were young women and children but in the course of 10 years the incidence in children has become lower and more and more cases are observed in adults. A further clinical report on 214 cases of kuru has recently been published (Hornabrook, 1968).

There have been few pathological reports in the literature on kuru (Klatzo, Gajdusek \& Zigas, 1959; Fowler \& Robertson, 1959; Neumann, Gajdusek \& Zigas, 1964; Kakulas, Lecours \& Gajdusek, 1967); these have established the fact that the disease is confined to the nervous system and is a subacute, degenerative condition. We ourselves have investigated thirteen cases of kuru; four male and nine female, with ages ranging from $4 \frac{1}{2}$ to 30 years (average $14 \frac{1}{2}$ years); the duration of the illness varied

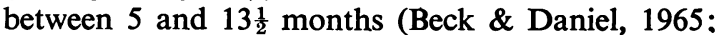
Beck, Daniel \& Gajdusek, 1965).

Macroscopically the brains appeared normal except that there was atrophy of the cerebellum which was most marked in the phylogenetically old 
part of the cerebellum (vermis and flocculo-nodular lobe) while the neocerebellum (hemispheres) was relatively better preserved. The weights of the brains were low as compared with established norms, but control cases from the same region of New Guinea showed equally low weights. Microscopically the most striking change was a severe degeneration of the cerebellum, in particular the paleo-cerebellum. The greatest nerve-cell loss was amongst the granule cells, which were very sparse, while the loss of Purkinje cells was not so great (Fig. 8) although many

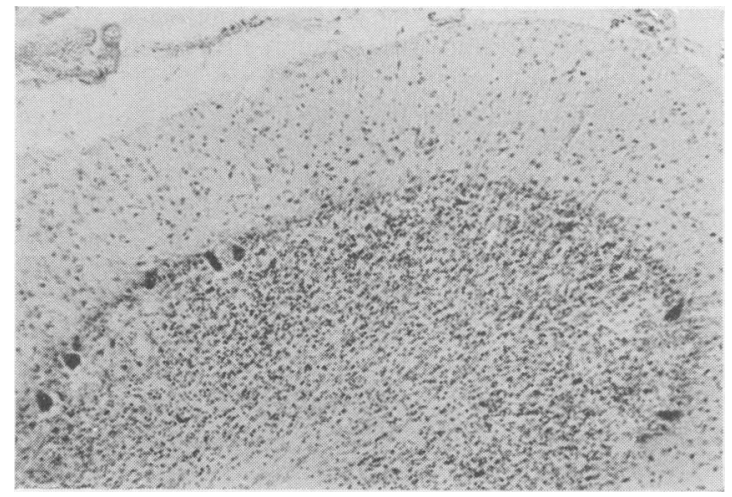

Fig. 8. Kuru. Cerebellum with great loss of Purkinje cells, those surviving being very atrophic. The loss of granule cells is even more severe (cf. Fig. 1). Nissl stain.

of those surviving looked abnormal and showed torpedo-like swellings on their axons (Fig. 9) and antler-like thickenings of their dendrites. In the molecular layer large numbers of phagocytic micro-

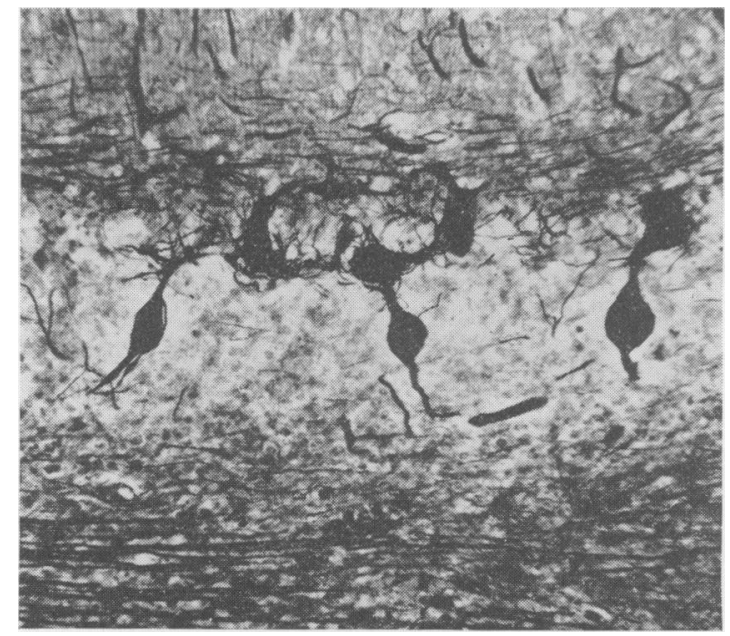

Fig. 9. Kuru. Cerebellum; the atrophic Purkinje cells often have torpedo-like swelling on their axons. GrosBielschowsky silver impregnation. glial cells were seen, many containing neutral fat. Astrocytes had proliferated and there was a dense fibrous gliosis (Fig. 10). A striking feature in some

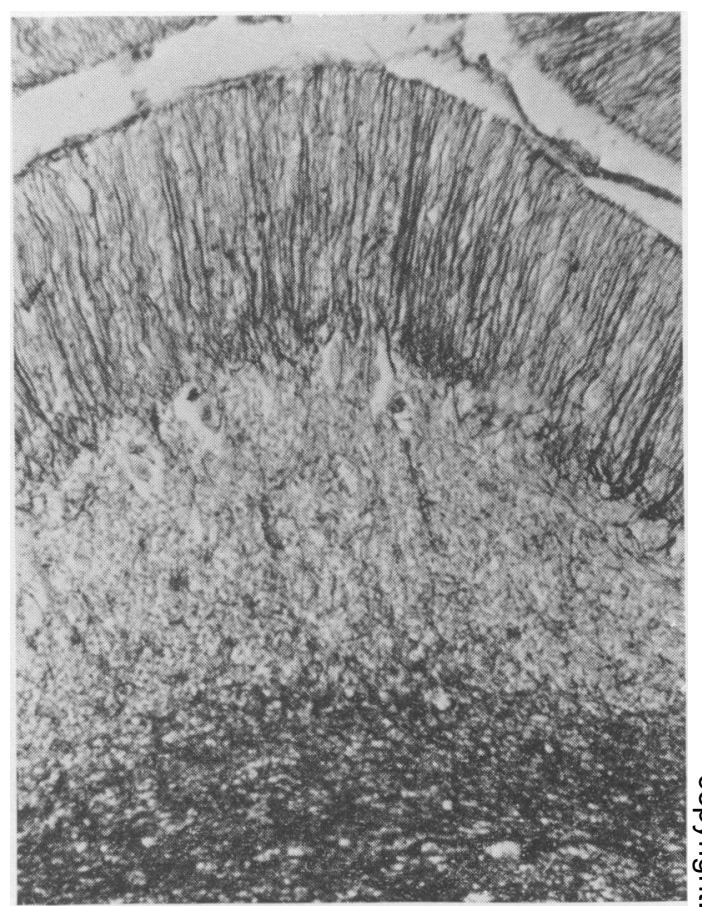

Fig. 10. Kuru. Cerebellum; as in scrapie (cf. Fig. 3) there is severe fibrous gliosis (dark staining fibres) in cortex and subcortical white matter. Holzer stain.

three-quarters of the cases was the presence of plaques, sometimes termed 'kuru plaques', which are periodic-acid-Schiff-positive, argentophilic, slightly positive with stains for amyloid and doubly refractile. The cerebellar white matter also showed some degeneration with a certain amount of neutral fat and subcortical fibrous gliosis, but sections stained for myelin did not show any obvious demyelination on naked eye inspection. In the brain-stem all nuclei with cerebellar connections showed degenerative changes; in particular the pontine nuclei and inferior olives were outlined by the dense fibrous gliosis (Figs. 11 and 12). About half of our cases showed a degeneration of the cortico-spinal tracts. Other changes included an abnormality of the hypothalamo-neurohypophysial system, coarse vacuolation of many of the large neurones in caudate nucleus and putamen, status spongiosus in limited parts of the cerebral cortex (Fig. 13) and basal ganglia and an astrocytic proliferation in the spongy areas (Fig. 14).

From the above description of the pathology of kuru the remarkable similarity between the abnormalities in this disease and scrapie becomes clear. 


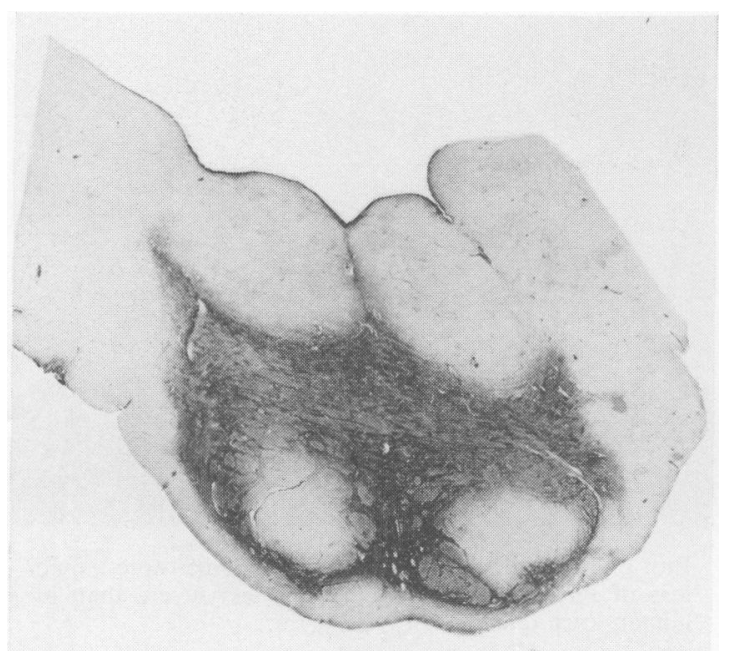

FIG. 11. Kuru. Pons; as in scrapie (cf. Fig. 4) the pontine nuclei are severely degenerated and contain a dense network of glial fibres (dark area). The tegmentum and the cortico-spinal tracts are spared. Holzer stain.

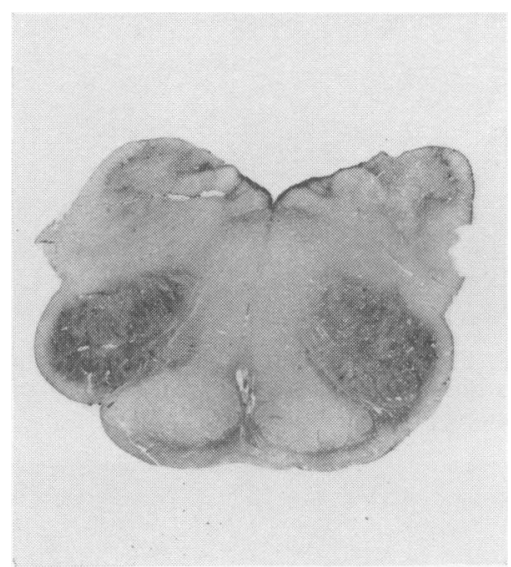

Fig. 12. Kuru. Medulla; the degenerated inferior olives contain a dense network of glial fibres, owing to which they stand out darkly on the photograph (compare with scrapie, Fig. 5). Holzer stain.

As mentioned before, the fact that scrapie could be transmitted to other animals led Gajdusek and his collaborators to attempt the transmission of kuru in a similar manner.

\section{Experimental kuru}

When chimpanzees were inoculated intracerebrally with a suspension of brain material from patients who had died of kuru, they developed, after 18 months or more, a clinical picture very similar to that of the human disease, with ataxia as the most striking sign. In most cases the disease was allowed

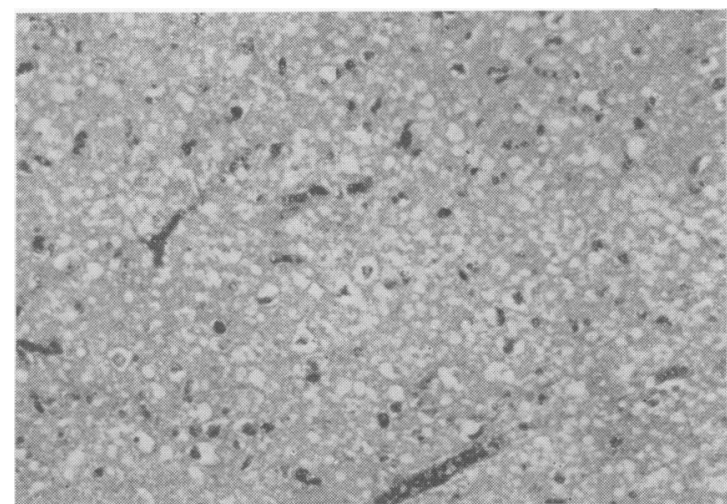

Fig. 13. Kuru. Cerebral cortex (gyrus cinguli) showing moderate degree of status spongiosus throughout all layers. $\mathrm{H} \& \mathrm{E}$.

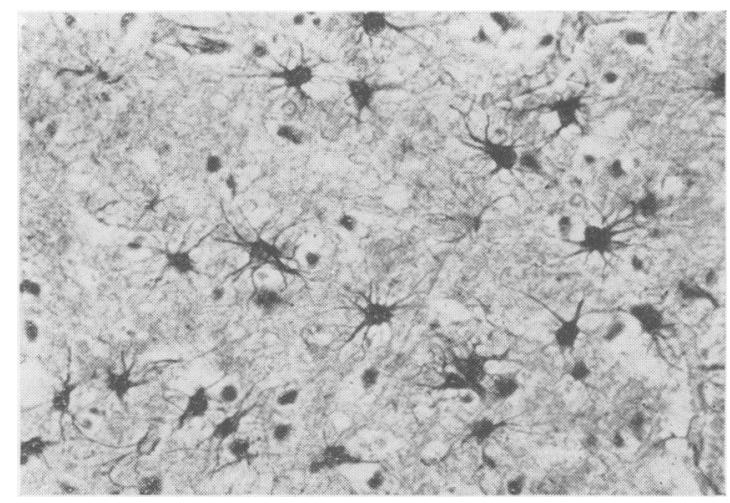

Fig. 14. Kuru. Cerebral cortex; in the spongy areas of the cortex astrocytes usually show some hypertrophy and proliferation. Cajal gold sublimate impregnation.

to progress to the terminal stages before the animals were killed (Beck et al., 1966).

At post-mortem no abnormalities were seen macroscopically throughout the body. However, severe changes were found histologically in the brain. The most striking and somewhat unexpected finding was a severe and extensive spongy degeneration of the grey matter (Fig. 15) which was associated with an intense proliferation and hypertrophy of astrocytes (Fig. 16). But whilst in the human disease such spongy areas were rather limited and often not very prominent, in the transmitted disease no area of grey matter was spared and, on the whole, status spongiosus dominated the picture. In the spongy areas there was a great loss of nerve cells. The cerebral white matter contained some neutral fat but clearly demyelination was not a basic feature of the disease, nor were inflammatory changes in any way prominent, though rarely a cuffed vessel might be seen. In the hypothalamo-neurohypophysial system 


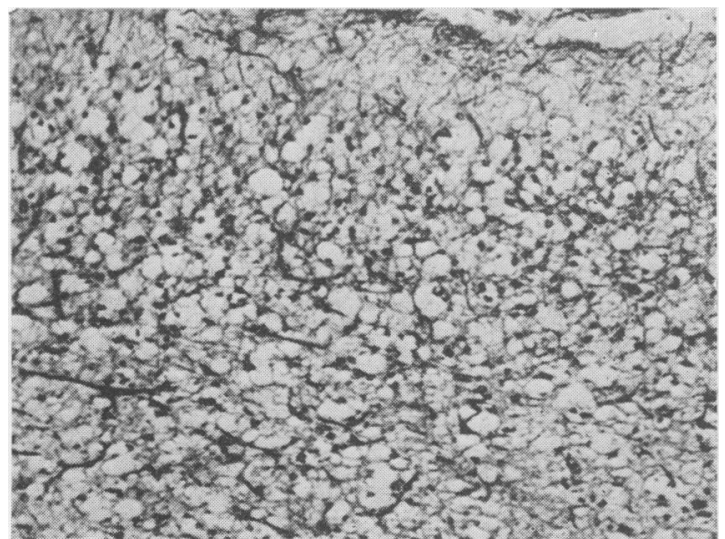

FIG. 15. Experimental kuru. Cerebral cortex showing very severe status spongiosus. Sponginess was a marked feature throughout most of the grey matter of the brain and was much more developed than in human kuru (cf. Fig. 13). H \& E.

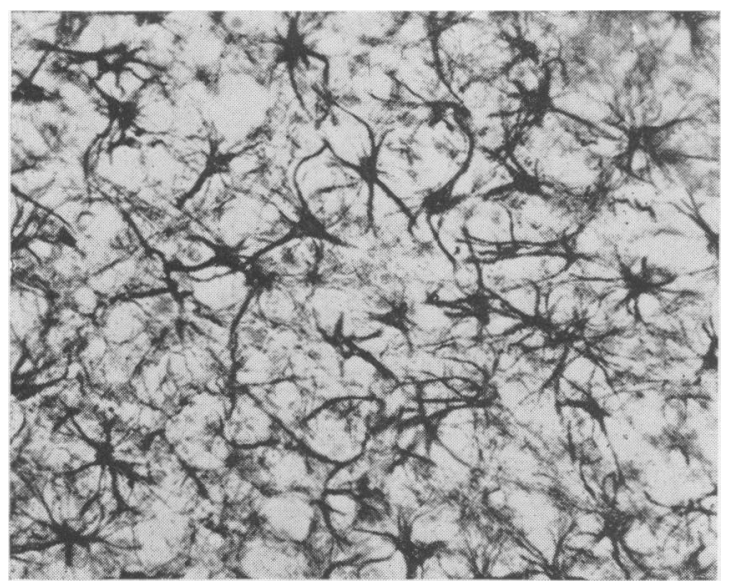

Fig. 16. Experimental kuru. Cerebral cortex; in the spongy grey matter the astrocytes showed hypertrophy and proliferation. Cajal gold sublimate impregnation.

and in the cerebellum and its connections (Figs. 17-19) the changes were similar to those in the human disease, though less marked.

\section{Subacute presenile polio-encephalopathy (Creutzfeldt- Jakob disease)}

In the early stages of studies on kuru Klatzo et al. (1959) compared kuru with Creutzfeldt-Jakob disease and although, generally speaking, cerebellar degeneration is not a prominent feature in the latter, most cases show status spongiosus. Even more striking is the similarity between experimental kuru and the ataxic form of subacute presenile polio-encephalopathy (Brownell \& Oppenheimer, 1965) since in the latter condition there is not only widespread status

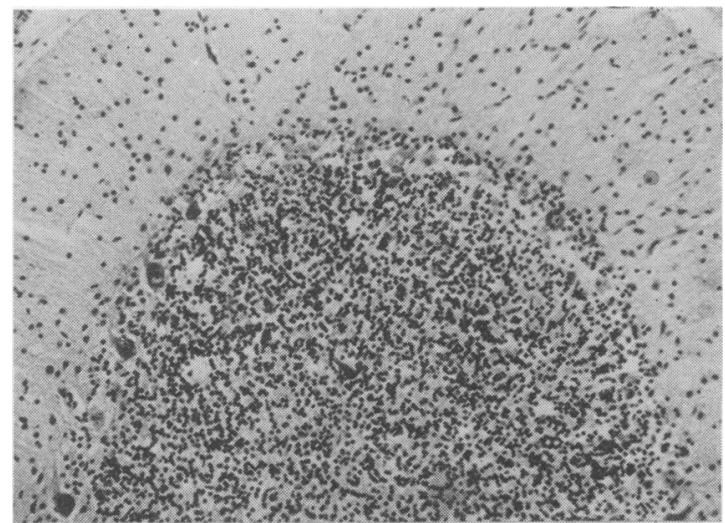

Fig. 17. Experimental kuru. Cerebellum; note some loss of Purkinje and granule cells, less severe than in human kuru (cf. Fig. 8). Nissl stain.

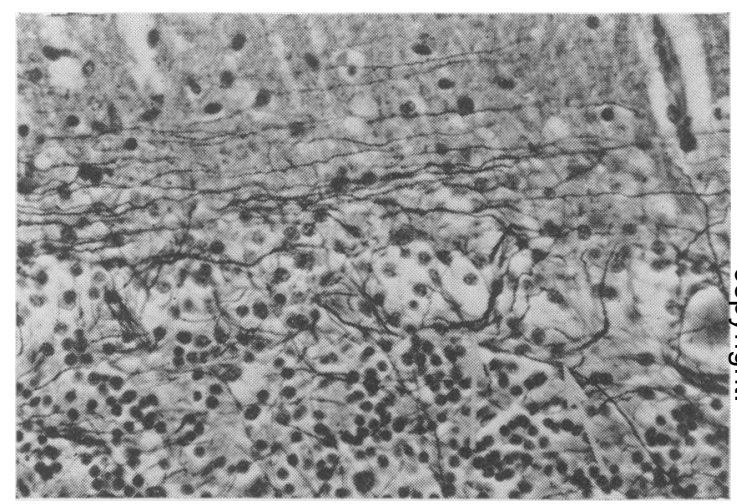

FIG. 18. Experimental kuru. Cerebellum; note empty baskets outlining the site of degenerated Purkinje cells. Glees silver impregnation.

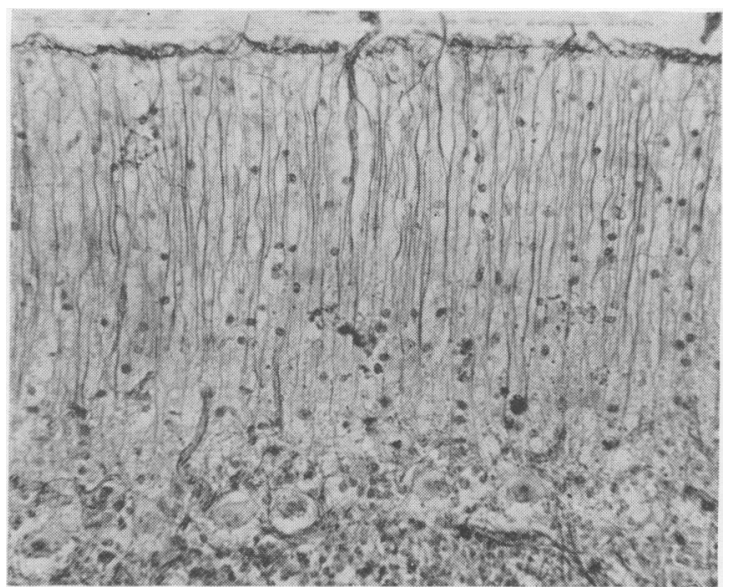

Fig. 19. Experimental kuru. Cerebellum; fibrous gliosis particularly marked in the molecular layer, but less developed than in human kuru (cf. Fig. 10). Holzer stain.

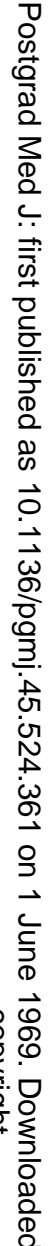


spongiosus in most cases but also cerebellar degeneration. Thus the possibility that this variety of Creutzfeldt-Jakob disease might also be transmissible seemed worth exploring.

The clinical features of subacute presenile polioencephalopathy have been briefly noted above. Pathologically the dominant change is a spongy degeneration of the grey matter (Fig. 20) which in some cases may lead to the destruction of large parts

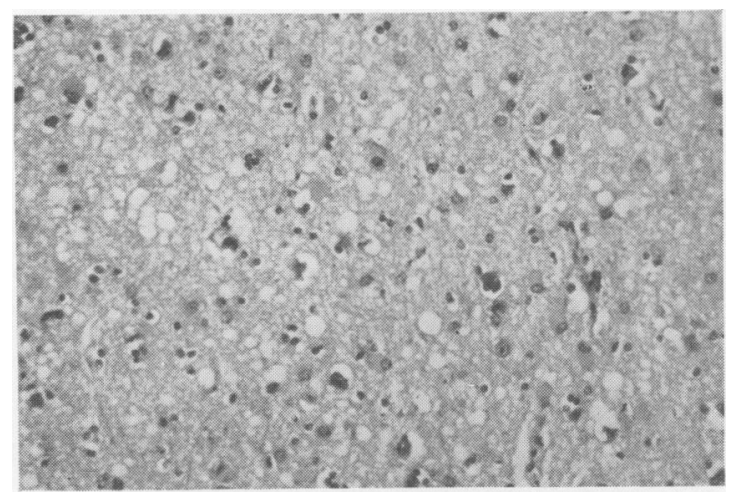

Frg. 20. Subacute presenile polioencephalopathy, cerebral cortex showing spongiform change (compare with kuru and experimental kuru, Figs. 13 and 15). H \& E.

of the cortex and basal ganglia. There is also considerable proliferation of astrocytes and microglial cells; senile plaques have not been found. The cerebellum often shows the type of degeneration found in kuru but both the paleo- and neocerebellum are affected to the same extent. A chimpanzee was inoculated with brain suspension from one patient with this disease, and subsequently after a latent period of 13 months became neurologically ill and was killed in the terminal stage of the disease. This animal's brain is still under investigation.

\section{Discussion}

The aetiological factor in these transmissible degenerative conditions of the central nervous system is at present unproven. There are certain indications that it may be a virus of yet unknown type acting in subjects with a genetic predisposition. The steadily shortening incubation-time seen in experimental kuru with repeated passage (and also in scrapie) would favour such a concept. On the other hand the extraordinary resistance of the scrapie agent to boiling in formalin and other severe insults suggests that if it is a virus, it is of a type not previously recognized. The same would apply to the absence of inflammatory reactions in the nervous system and the fact that the host does not appear to develop antibodies. A recent review on the possible nature of the agent in scrapie will be found in Hunter (1969).
So far a search for a virus in brain material from scrapie and kuru, both by means of tissue culture and electron microscopy, has failed to produce positive findings.

It should be emphasized that all the conditions described primarily affect the grey matter and that any degeneration of the white matter in these diseases is to be regarded as secondary to destruction of the nerve-cell. With the death of the nerve-cell its axon degenerates and the myelin sheath breaks up. These diseases should, therefore, be strictly distinguished from primary degenerations of the myelin, the best example of which is disseminated sclerosis.

The ability to transmit these subacute degenerative diseases to experimental animals will, it is to be hoped, lead to a rapid increase in knowledge. Although, as a result of the success in transmitting kuru, material from patients with many other chronic or subacute neurological diseases has been inoculated intracerebrally into a wide range of species, kuru and spongiform encephalopathy are, so far, the only two which have given positive results.

\section{Acknowledgments}

We are grateful to Dr D. C. Gajdusek and Dr C. J. Gibbs, $\mathrm{Jr}$ for giving us the brains of the kuru patients and those of the chimpanzees. The original work described in this paper was supported by the Nuffield Foundation and the Research Fund of the Bethlem Royal and the Maudsley Hospitals. We thank the editors of Brain, of the Lancet, and the Monograph on Slow, Latent, and Temperate Infections for permission to reproduce figures.

\section{References}

Beck, E. \& Daniel, P.M. (1961) Degeneration and regeneration in the hypothalamus. Proc. Anat. Soc. Great Britain, p. 60. Taylor \& Francis, London.

BECK, E. \& DANIEL, P.M. (1965) Kuru and scrapie compared: are they examples of system degeneration? Slow, Latent and Temperate Virus Infections (Ed. by D. C. Gajdusek, C. J. Gibbs and M. Alpers), p. 85. National Institute of Neurological Diseases and Blindness Monograph No. 2. U.S. Government Printing Office, Washington.

BeCK, E., Daniel, P.M., Alpers, M., Gajdusek, D.C. \& GIBBS, C.J., JR (1966) Experimental 'kuru' in chimpanzees: a pathological report. Lancet, ii, 1056.

Beck, E., Daniel, P.M. \& Gajdusek, D.C. (1966) A comparison between the neuropathological changes in kuru and in scrapie, a system degeneration. Proc. Vth Int. Congr. Neuropath., p. 213. Excerpta Medica.

Beck, E., Daniel, P.M. \& PARRY, H.B. (1964) Degeneration of the cerebellar and hypothalamo-neurohypophysial systems in sheep with scrapie; and its relationship to human system degenerations. Brain, 87, 153.

BEVERIDGE, W.I.B. (1961) The Art of Scientific Investigation. Mercury Books, London.

Brownell, B. \& OpPenheimer, D.R. (1965) An ataxic form of subacute presenile polioencephalopathy (CreutzfeldtJakob disease). J. Neurol. Neurosurg. Psychiat. 28, 350.

CAMMERMEYer, J. (1960) The post-mortem origin and mechanism of neuronal hyperchromatosis and nuclear pyknosis. Exp. Neurol. 2, 379. 
Cuillé, J. \& Chelle, P.L. (1939) Investigations of scrapie in sheep. Vet. Med. 34, 417.

Fowler, M. \& Robertson, E.G. (1959) Observations on kuru. III. Pathological features in five cases. Aust. Ann. Med. 8, 16.

GAJDUSEK, D.C. (1963) Kuru. Trans. Roy. Soc. tropl. med. Hyg. 57, 151.

GaJduSEK, D.C. (1965) Kuru in New Guinea and the origin of the NINDB study of slow. latent, and temperate virus infections of the nervous system of man. Slow, Latent and Temperate Virus Infections (Ed. by D. C. Gajdusek, C. J. Gibbs and M. Alpers), p. 3. National Institute of Neurological Diseases and Blindness Monograph No. 2. U.S. Government Printing Office, Washington.

GaJduseK, D.C. \& GibBs, C.J., JR (1964) Attempts to demonstrate a transmissible agent in kuru, amyotrophic lateral sclerosis, and other subacute and chronic nervous system degenerations of man. Nature (Lond.), 204, 257.

GajduseK, D.C., GibBs, C.J., JR \& AlPers, M. (1966) Experimental transmission of a kuru-like syndrome to chimpanzees. Nature (Lond.), 209, 794.

Gajdusek, D.C., GibBs, C.J., JR \& Alpers, M. (1967) Transmission and passage of experimental 'kuru' to chimpanzees. Science, 155, 212.

GajduseK, D.C. \& Zigas, V. (1957) Degenerative disease of the central nervous system in New Guinea. The endemic occurrence of 'kuru' in the native population. New Engl. J. Med. 257, 974.

Gibbs, C.J., JR, GaJduseK, D.C., Asher, D.M., Alpers, M.P., Beck, E., Daniel, P.M. \& Matthews, W.B. (1968) Creutzfeldt-Jakob disease (spongiform encephalopathy): transmission to the chimpanzee. Science, 161, 388.

GoRDON, W.S. (1946) Advances in veterinary research. Louping-ill, tick-borne fever, and scrapie. Vet. Rec. 58, 516.

HaDlow, W.J. (1959) Scrapie and kuru. Lancet, ii, 289.

HadLow, W.J. (1961) The pathology of experimental scrapie in the dairy goat. Res. vet. Sci. 2, 289.
HoRnABROOK, R.W. (1968) Kuru-a subacute cerebellar degeneration. Brain, 91, 53.

HunTER, G.D. (1969) The chemical nature of the scrapie agent. Symposium on Virus Diseases of the Nervous System (Ed. by C. W. M. Whitty). Blackwell Scientific Publications, Oxford.

JoNes, D.P. \& NeviN. S. (1954) Rapidly progressive cerebral degeneration (subacute vascular encephalopathy) with mental disorder, focal disturbances and myoclonic epilepsy. J. Neurol. Neurosurg. Psychiat. 17, 148.

KaKulas, B.A., Lecours, A.-R. \& GajduseK, D.C. (1967) Further observations on the pathology of kuru. J. Neuropath. exp. Neurol. 26, 85.

Klatzo, I., GajduseK, D.C. \& Zigas, V. (1959) Pathology of kuru. Lab. Invest. 8, 799.

Koenig, R.S. \& Koenig, H. (1952) An experimental study of post mortem alterations in neurons of the central nervous system. J. Neuropath. exp. Neurol. 11, 69.

NeumanN, M.A., GajduseK, D.C. \& Zigas, V. (1964) Neuropathologic findings in exotic neurologic disorders among natives of the highlands of New Guinea. $J$. Neuropath. exp. Neurol. 23, 486.

Nevin, S., McMenemey, W.H., Behrman, S. \& Jones, D.P. (1960) Subacute spongiform encephalopathy-a subacute form of encephalopathy attributable to vascular dysfunction (Spongiform cerebral atrophy). Brain, 83, 519.

Palmer, A.C. (1959) Scrapie: a review of the literature. Vet. Rev. Ann. $5,1$.

PARRY, H.B. (1962) Scrapie: a transmissible and hereditary disease of sheep. Heredity, 17, 75.

PARRY, H.B. (1969) Scrapie. Symposium on Virus Diseases of the Nervous System (Ed. by C. W. M. Whitty). Blackwell Scientific Publications, Oxford

Pattison, I.H. \& Smith, K. (1963) Histological observations 0 on experimental scrapie in the mouse. Res. vet. Sci. 4, 269

Sigurdsson, B. (1954) Rida, a chronic encephalitis of sheep Brit. vet. J. 110, 341 . 